
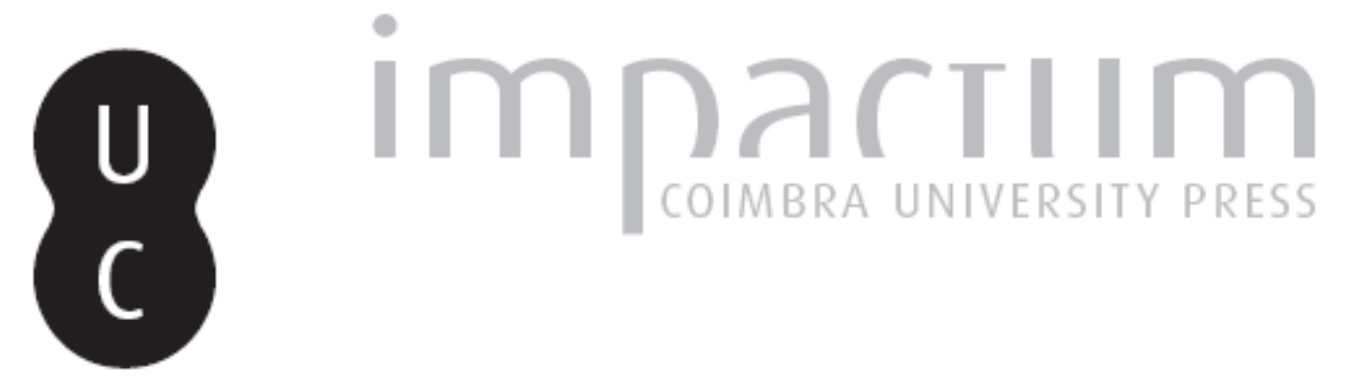

\title{
El sociolecto femenino en la Archaia y Nea Griegas
}

\section{Autor(es): $\quad$ Navarro Martínez, Vivian Lorena}

Publicado por: Imprensa da Universidade de Coimbra

URL persistente:

URl:http://hdl.handle.net/10316.2/42292

DOI:

DOI:https://doi.org/10.14195/2183-7260_61_5

Accessed : $\quad$ 26-Apr-2023 11:15:21

A navegação consulta e descarregamento dos títulos inseridos nas Bibliotecas Digitais UC Digitalis, UC Pombalina e UC Impactum, pressupõem a aceitação plena e sem reservas dos Termos e Condições de Uso destas Bibliotecas Digitais, disponíveis em https://digitalis.uc.pt/pt-pt/termos.

Conforme exposto nos referidos Termos e Condições de Uso, o descarregamento de títulos de acesso restrito requer uma licença válida de autorização devendo o utilizador aceder ao(s) documento(s) a partir de um endereço de IP da instituição detentora da supramencionada licença.

Ao utilizador é apenas permitido o descarregamento para uso pessoal, pelo que o emprego do(s) título(s) descarregado(s) para outro fim, designadamente comercial, carece de autorização do respetivo autor ou editor da obra.

Na medida em que todas as obras da UC Digitalis se encontram protegidas pelo Código do Direito de Autor e Direitos Conexos e demais legislação aplicável, toda a cópia, parcial ou total, deste documento, nos casos em que é legalmente admitida, deverá conter ou fazer-se acompanhar por este aviso.

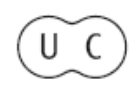




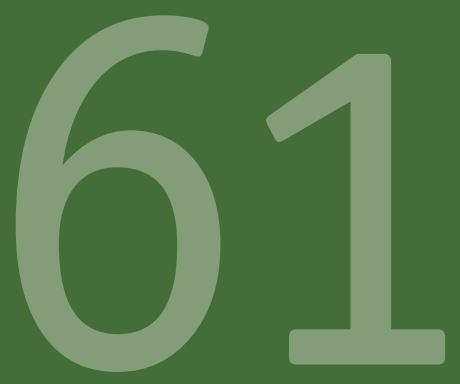

\title{
BOLETIM DE
}

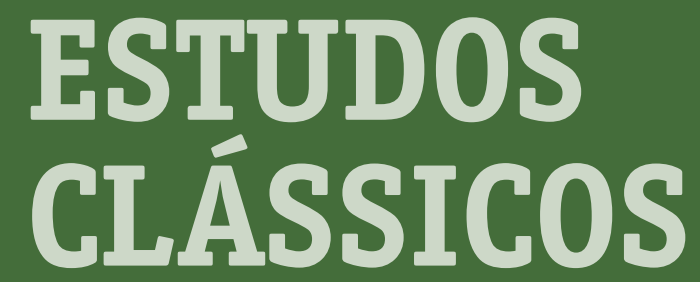

\author{
ASSOCIAÇÃO \\ PORTUGUESA \\ DE ESTUDOS \\ CLÁSSICOS \\ INSTITUTO \\ DE ESTUDOS \\ CLÁSSICOS
}




\title{
EL SOCIOLECTO FEMENINO EN LA ARCHAIA Y NEA GRIEGAS
}

\section{THE FEMALE SOCIOLECT IN GREEK ARCHAIA AND NEA}

\author{
VIVIAN LORENA NAVARRO MARTÍNEZ \\ UNIVERSIDADE DE COIMBRA - UNIVERSITAT DE VALÈNCIA \\ vilona@alumni.uv.es
}

Resumen: Generalmente se considera que el género cómico es uno de los que mejor reflejan la realidad social del momento, aunque es importante distinguir cuándo la invención de los poetas predomina sobre la verosimilitud de los hechos auténticos. Esta realidad se refleja también en el ámbito lingüístico, en el cual se pueden distinguir diferentes estratos y condiciones sociales, dependiendo del tipo de lenguaje que empleen los personajes. En nuestro estudio nos ocupamos de una determinada parte de la sociedad, la femenina, y de la comedia de Aristófanes y Menandro. Nuestro objetivo es ofrecer una síntesis de las características más destacadas de los sociolectos mostrados por ambos cómicos, tratando de insistir en su evolución.

Palabras Clave: Comedia; mujeres; sociolecto; sociedad; habla.

Abstract: The comic genre is generally considered one of that better reflects the social reality of the moment, although it is important to distinguish when the invention of poets predominates over the likelihood of the real facts. This realism is also reflected in the linguistic field, in which we can distinguish different strata and social conditions, depending on the type of language that the characters use. In our study we deal with a certain part of society, women, and the comedy 
of Aristophanes and Menander. Our aim is to provide a synthesis of the relevant features of the sociolects shown by both comics, trying to insist on this evolution.

Keywords: Comedy; women; sociolect; society; speech.

En términos generales, entendemos que un sociolecto es la forma en que un determinado grupo o estrato social emplea una lengua, y su existencia se debe a diversos elementos de la vida de los individuos (clase social, nivel de educación, cultura de procedencia, etc.). Nuestro estudio se centra en el sociolecto femenino presente en la comedia griega antigua, lo que en sí es un obstáculo importante, ya que las fuentes que nos hablan de mujeres y de su forma de hablar son básicamente escritas. El problema va más allá, pues dichas fuentes se reducen a obras pertenecientes a ciertos géneros literarios, como el teatro, la oratoria o la filosofía, cultivados por hombres. Por tanto, vamos a estudiar el sociolecto femenino desde una perspectiva masculina. En cuanto a la elección de la comedia como base de nuestro artículo, nos hemos apoyado en la idea generalizada de que es el género literario que más y mejor refleja la realidad social del momento, aunque es necesario ser conscientes de que hay que ir con cierto cuidado, pues es importante distinguir cuándo la invención de los cómicos predomina sobre la verosimilitud de los hechos auténticos. Así, hemos de tener presente que la comedia se desenvuelve entre la fantasía y la realidad, se trata de una distorsión que refleja no como era realmente la sociedad en la antigua Atenas, sino más bien cómo la misma sociedad se veía a ella misma en el espacio de la representación teatral. Por ello no hemos de pensar que las mujeres hablaban exactamente como lo plasman Aristófanes y Menandro, sino que nos encontramos ante una aproximación a la realidad. ${ }^{1}$

1 Mossé 1990: 119. "Hay que buscar en el teatro (...) información sobre la condición real de la mujer ateniense". 
Es de suponer que en la comedia griega no sólo está representada la forma en que las mujeres empleaban el griego antiguo, sino que los poetas también supieron exponer la forma de hablar de otros estratos sociales, con el objetivo principal de dar realismo a sus personajes y promover la comicidad. Señalamos al respecto el artículo de López Eire, que distingue hasta once sociolectos diferentes en la comedia de Aristófanes, entre los que incluye los de género. ${ }^{2}$ Así pues, encontramos multitud de sociolectos, atendiendo a los diferentes estratos sociales de la polis ateniense. Paralelamente a esta idea hay tres niveles del lenguaje, ya no en las obras del propio Aristófanes, sino en el mismo ático hablado: una lengua "intermedia" o estándar de la polis, una "finolis" o refinada de los habitantes de la ciudad y después una "barriobajera" o vulgar, propia de aquellos habitantes de Atenas que no tenían un destacado nivel educativo. ${ }^{3}$ La primera se correspondería con los vocablos que podemos encontrar en todos los géneros literarios, que combinaría elementos del arcaizante dialecto ático con las innovaciones que los jonios, al llegar a la polis, fueron introduciendo. ${ }^{4}$ La segunda es una lengua refinada, alejada de la que se empleaba en el día a día, que habría sido promocionada sobre todo por los sofistas y los rétores. La tercera comprendería aquellas palabras u expresiones que podemos localizar en la comedia, que tradicionalmente se atribuyen a aquellos hablantes con escasa formación o cultura. Cabe también indicar que al lado de estos niveles del lenguaje encontramos otros: las jergas, la lengua poética, los arcaísmos, los dialectos y los localismos áticos. Sin embargo, ¿a qué nivel pertenecería exactamente la lengua de la comedia? No podemos afirmar que en este género se emplee única y

2 López Eire 1986: 270-273.

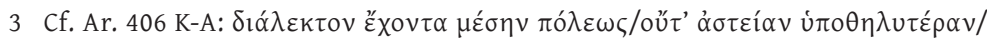

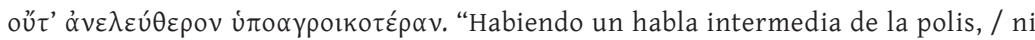
tan finolis de la capital, / ni tan vulgar de barrio bajo.” Melero 1984: 203-210, 204. Dover 1987: 242-243.

4 Redondo 1997: 313-328, 321. 
exclusivamente el habla vulgar, ya que sabemos que los cómicos saben adaptar los personajes a sus respectivas naturalezas y al efecto cómico deseado. Por ejemplo, en el caso de la parodia de la tragedia o de un discurso oratorio, vamos a encontrar un nivel del lenguaje elevado o más estandarizado. También debemos considerar que en la comedia hay características lingüísticas que pertenecen al ámbito del habla familiar, que se encuentra en una posición intermedia entre la lengua estándar y la vulgar. Por otra parte, no necesariamente debemos confundir "lengua vulgar" con "lengua conversacional", es decir, aquella que se usa en ámbitos informales; como tampoco debemos relacionar todos los niveles del lenguaje conversacional sólo con la comedia. ${ }^{5}$ Por tanto, no podemos adscribir la lengua de la comedia a un único y exclusivo nivel del lenguaje.

Por otra parte, cabe señalar varios factores metodológicos que determinan sustancialmente nuestro estudio. En primer lugar, el hecho de que la sociolingüística griega antigua no cuenta con una tradición de investigación afianzada, por lo que nos topamos ante una diversidad de estudios que defienden perspectivas contrarias que no nos permiten avanzar una cierta corriente de investigación sociolingüística del griego antiguo. ${ }^{6}$ Otro hecho es que, como afirma Melero, ${ }^{7}$ cuando nos proponemos realizar un análisis sobre un fragmento u obra cómica completa de un período específico, debemos evitar caer en generalizaciones, ya que, aunque los cómicos que comparten un mismo período tengan algunas características estilísticas similares, esto no significa que todos escriban de igual forma. Por ello, si Aristófanes o Menandro componen y crean de una manera determinada, esto no implica que las características de la Archaia o la Nea sean exclusivamente las que

5 Dickey 1995: 257-271, 260.

6 Nos referimos a los estudios que defienden la investigación de los sociolectos del griego antiguo, y a aquellos que niegan la posibilidad y efectividad de este análisis. Redondo 2002: 202-203.

7 Melero 1984: 204. 
podemos observar en sus obras, aunque sean sus máximos representantes. Por otra parte, como hemos dicho, debemos tener en cuenta que el estudio del sociolecto femenino se encuentra condicionado por el hecho de que los testimonios que tenemos son escritos y, además, por hombres. Por tanto, la realidad representada sobre las mujeres se encuentra distorsionada. Es más, en el caso de la comedia hablamos de una realidad mezclada con la fantasía, por lo que extraer datos auténticos de la vida y forma de hablar de las féminas es una tarea en sí bastante compleja. Otro hecho a tener en cuenta es la manipulación de la lengua, en función del efecto dramático deseado, por parte de Aristófanes y Menandro. Al estudiarlos hay que tener presente la distancia que existe entre la lengua que plasman y aquella realmente hablada por las mujeres en la sociedad de su época. Por último, señalamos la relevancia que tiene el factor de la marginalidad del grupo femenino en la Atenas de la época, atendiendo al hecho de que los pocos casos en los que podemos ver una real participación de la mujer pertenecen casi siempre al ámbito de la religión. ${ }^{8}$ Es más, el ideal tradicional de mujer griega evoca una imagen doméstica y sumisa, sin importancia en la esfera pública, siendo cualquier transgresión de estas normas un hecho altamente reprochable. Desde el momento en que una mujer libre llegaba a ser esposa y pasaba a formar parte del oikos del marido, ésta quedaba relegada esencialmente a las tareas de preservar, cuidar y organizar este oikos, para cuya supervivencia debía proporcionar una descendencia legítima. ${ }^{9}$ Así pues, la mujer ateniense ideal debe ser una figura que pase desapercibida, y la simple mención de su nombre en público implica una grave deshonra. ${ }^{10}$

Centrándonos ya en el análisis y estudio del sociolecto femenino, cabe decir que no trataremos términos "exclusivamente" empleados

\footnotetext{
8 Fögen 2010: 312-113.

9 Cortés Gabaudán 2005: 39-62.

10 Sommerstein 2009: 43-69.
} 
por mujeres, sino "preferentemente" usados por ellas. ${ }^{11}$ Por otra parte, seguiremos un determinado orden que, en rasgos generales, hemos observado en los diversos estudios analizados, y que comprende los ámbitos en los que inciden fundamentalmente las características de la dicción femenina: la fonética y fonología, los adjetivos, los diminutivos, los verbos, las formas de dirigirse o expresión de la función fática, los juramentos, las partículas y la sintaxis. ${ }^{12}$ Nos basaremos en un corpus de textos que abarca fundamentalmente aquellas comedias conservadas en las que vemos una actuación femenina de cierta importancia: Lisístrata, Tesmoforiantes y Asambleístas de Aristófanes, El misántropo, La samia, La rapada y El arbitraje de Menandro.

En primer lugar, para analizar las características del nivel fonético y fonológico, señalamos determinadas referencias de la Antigüedad que resultan interesantes.

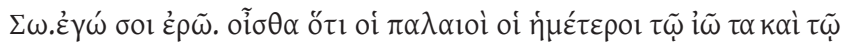

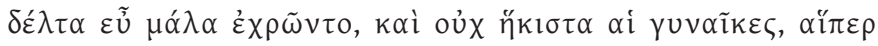

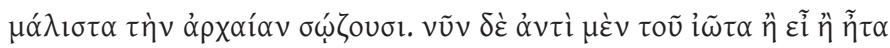

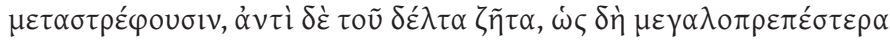

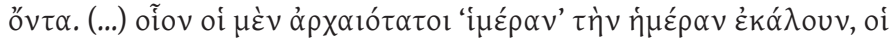

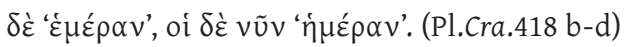

"Sócrates: Yo te lo diré. Ya sabes que nuestros antepasados utilizaban mucho la iota y la delta, y sobre todo las mujeres, las que precisamente más conservan la forma de hablar antigua. Pero ahora en lugar de la iota cambian a la épsilon o la eta, y en lugar de la delta, a la zeta, como si fuesen más magnificentes. (...) Igual que los más antiguos llamaban al día himéran, otros heméran, y los de ahora hèméran".

11 “Not just of' sex-exclusive' expressions, but of 'sex-preferential' expressions, locutions which one sex uses occasionally, the other regularly". Bain 1984: 30.

12 Cf. Redondo 2002: 201-224. Sommerstein 1995: 61-85. Fögen 2010: 311-326. Duhoux 2004: 131-145. Bain 1984: 24-42. 
Platón está calificando al habla femenina de arcaizante, sin embargo los cambios fonéticos que nos expone no pueden ser considerados rasgos arcaizantes, sino más bien innovaciones fonológicas propias de un dialecto ático no estándar, que se puede encontrar atestiguado en inscripciones o grafiti de la época. ${ }^{13}$ Podría decirse que este tipo de dialecto era más empleado por las mujeres que por los hombres, que estaban más habituados al ático estándar, utilizado en los ámbitos de la esfera pública en los que se desenvolvían y se habían educado.

Equidem cum audio socrum meam Laeliam - facilius enim mulieres incorruptam antiquitatem conservant, quod multorum sermonis expertes ea tenent semper, quae prima didicerunt - sed eam sic audio, ut Plautum mihi aut Naevium videar audire (Cic. De or.3. 45)

En verdad cuando oigo a mi suegra Lelia - pues las mujeres conservan íntegra la tradición con más facilidad, porque ellas, al no tomar parte nunca en la conversación de la multitud, mantienen lo primero que aprendieron - de tal modo la escucho, que me parece oír a Plauto o a Nevio.

Mediante el ejemplo de Lelia, la suegra de Craso, vemos que entre las aristócratas romanas parecía ser usual no adoptar innovaciones del latín en su forma de hablar, debido en esencia a su escaso contacto con el ámbito público, lo que explicaría la abundancia de elementos arcaizantes en su dicción. ${ }^{14}$ Centrándonos de nuevo en Grecia, la explicación parece ser similar: al estar la mujer excluida de la vida pública, no podía tomar parte de la asimilación de las innovaciones lingüísticas que estaban surgiendo desde el siglo V a. C. en Atenas, por lo que su dicción quedó caracterizada por la abundancia de formas arcaizantes.

13 Sommerstein 1995: 81-83. Willi 2003: 161-162, 171, 194-195.

14 Fögen 2010: 318-319. 
A lo largo de nuestro estudio veremos que esta abundancia de arcaísmos está bien reflejada por parte de nuestros cómicos.

Rasgo distintivo de la dicción de las mujeres parece ser la reducción

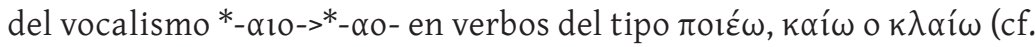
Ar.Lys.9, 320, 333; Th.240, 280). Esta característica también la podemos observar en boca de Fidípides (Ar. Nu.870-875), que utiliza el término крદ́ $\mu_{\alpha 10}$, mostrando su escasa atención hacia las enseñanzas de Sócrates, quien lo tacha de infantil. No sería descabellado pensar que Aristófanes, en este caso, está caracterizando a personas carentes de conocimientos y educación, como son las mujeres y los niños, con esta particularidad fonética. Por otra parte, la geminación de fonemas consonánticos es otra constante que está relacionada con la dicción familiar, rasgo que tiene

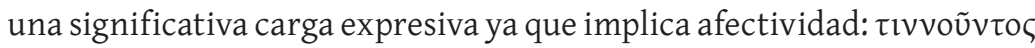

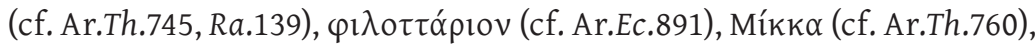

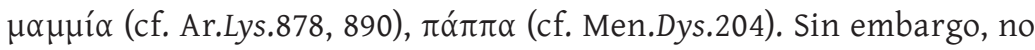
es un elemento exclusivo del sociolecto femenino, pues pertenece a la dicción familiar, a la que no solo corresponde la lengua de las mujeres, sino también la de los esclavos, los niños o los campesinos. También cabe destacar la presencia copiosa de crasis y elisiones en los parlamentos femeninos en comparación con los masculinos, por ejemplo,

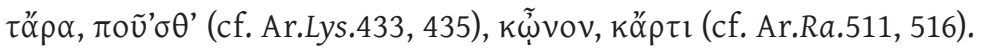

Hay determinadas formas adjetivales que aparecen con frecuencia en el habla femenina de las comedias de Aristófanes y Menandro. Es interesante el análisis que realiza Sommerstein, ${ }^{15} \mathrm{el} \mathrm{cual} \mathrm{indica} \mathrm{que} \mathrm{los}$

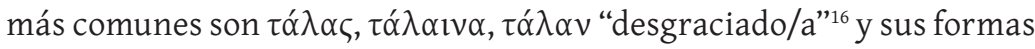
superlativas, como $\tau \alpha \lambda \alpha \alpha^{\prime} \tau \tau \alpha \tau \varepsilon$ y $\tau \alpha \lambda \alpha v \tau \alpha \dot{\tau} \tau \eta ; \delta u ́ \sigma \mu о \rho \circ$ " "desdichado/a",

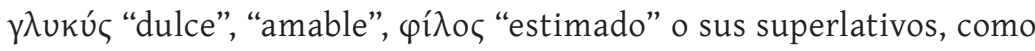

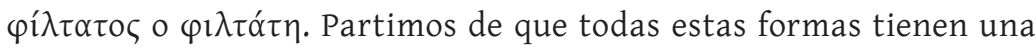
clara carga emocional que indican tanto angustia ( $\tau \alpha \dot{\alpha} \lambda \alpha \varsigma, \tau{ }^{\prime} \lambda \alpha \imath v \alpha$,

15 Sommerstein 1995: 68-72.

16 Bain señala su doble significado: "miserable", que haría referencia a la compasión, y “obstinado/a”, que expresaría una intención de censura o reproche. Bain 1984: 34. 


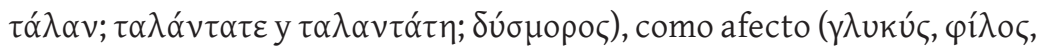

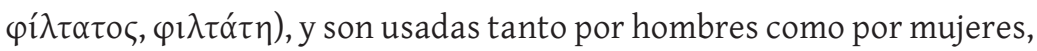
aunque estas últimas las utilizan más en las obras de ambos cómicos. Los casos en los que las mujeres usan estos términos son, por ejemplo, cuando se dirigen a los hijos (cf. Ar.Lys.889, 890) o a personas con las que se guarda un trato afectuoso o cordial (cf. Ar.Pl.684, 1046, 1060; Th.760). En cuanto a su uso "mixto" podemos encontrar las formas de

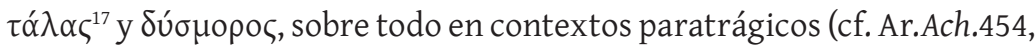
1203), en los que se pretende dar una imagen de afectación, auténtica o no, o en los que se imita el sermo tragicus (cf. Men.Sam.69, 369-370, $398,568) .{ }^{18}$ También, en aquellas situaciones en las que un hombre está imitando la dicción femenina (cf. Men.Sam.252) o, en el caso concreto

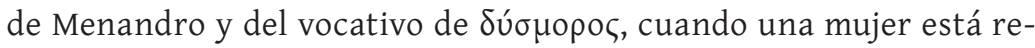
prendiendo a un hombre (cf. Men.Epit.468; Sam.69, 255). El uso por parte

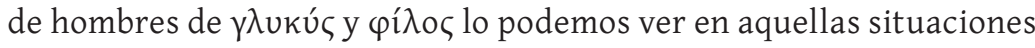
en que se refieren a una mujer que se desea sexualmente o se ama (cf. Ar. Lys.872; Th.1192; Ec.1046; Men.Dys.669; Epit.888).

Otro elemento muy característico de la dicción femenina y que queda fuertemente atestiguado en las comedias de los poetas que nos ocupan es el uso del diminutivo. Como sabemos, una de las cualidades de los diminutivos es la de añadir a las palabras un matiz emotivo y afectivo. Teniendo en cuenta la carga generalmente afectuosa de los adjetivos que hemos examinado anteriormente y que el sociolecto femenino hunde sus raíces en la dicción familiar, en la que el uso del diminutivo es característico, no es de extrañar que este elemento sea común en la forma de hablar de las mujeres. Así pues, el uso abundante de diminutivos es uno de los principales rasgos del sociolecto femenino reflejado en la comedia, además de ser consecuencia de la tradicional

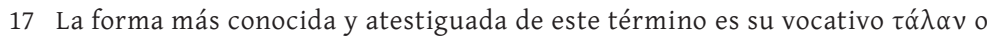

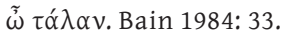

18 En el caso de Menandro se observa que estas formas son muy características del lenguaje de las mujeres, especialmente de aquellas de bajo estrato social. Macua 1997: 160 . 
concepción griega de la mujer como ser más emocional que el hombre. ${ }^{19}$ Sin embargo, no podemos decir que sólo las mujeres empleen diminutivos, pues en Aristófanes observamos casos en los que hombres y niños los utilizan, tanto en sentido afectivo como despectivo, por ejemplo,

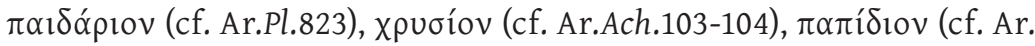

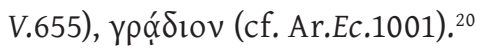

En cuanto a la expresión de la función fática o los términos en los que las mujeres se dirigen a otras personas o a ellas mismas, encontramos los siguientes rasgos característicos. Sommerstein afirma que tanto en Aristófanes como en Menandro no hay formas de dirigirse reservadas exclusivamente a las mujeres, excepto las formas yúval "mujeres" y $\gamma \rho \alpha \tilde{u}$ "vieja", teniendo ésta última un sentido despectivo. También

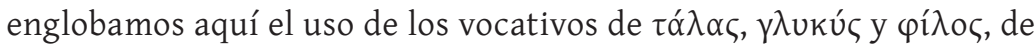

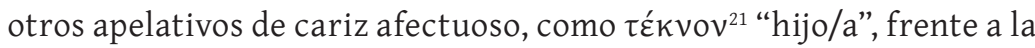

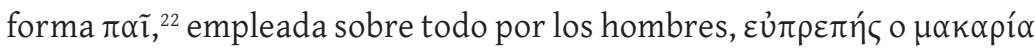
"guapa", "buena amiga" (cf. Men.Epit.484, 873), y de los diminutivos. Todas son formas con una evidente carga emocional y afectiva, que son empleadas fundamentalmente por personajes femeninos o afeminados para dirigirse a otros con los que se guarda una cierta relación. Sin embargo, esto no implica que, en determinados momentos, no sean puestos

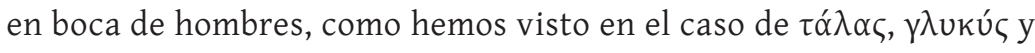

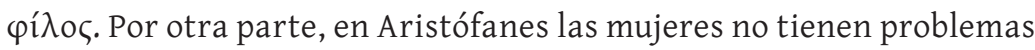
en dirigirse a otras mujeres con su propio nombre, pero no ocurre lo mismo con los hombres, mientras que en Menandro esta distinción ya no se da y las mujeres se dirigen a los hombres por su nombre sin

19 Fögen 2010: 322-323.

20 Dickey y Sommerstein indican que en las comedias de Menandro $\gamma \rho \alpha \tilde{u}$ y $\gamma \rho \alpha \alpha_{\delta} \delta$ เov son sólo usados para dirigirse a esclavas o ex esclavas. Dickey 1996: 82. Sommerstein 1995: 75.

21 Bain sugiere que, aparte de pertenecer al sociolecto femenino en Menandro, sería un arcaísmo originalmente usado por los hombres, pero perduró en el habla de las mujeres. Bain 1984: 38-39.

22 Para un conocimiento más extenso, cf. Dickey 1996: 65-72. 
problemas. Por otra parte, los vocativos de Aristófanes son más largos, elaborados y variados que los de Menandro e incluso a veces el poeta crea algunos nuevos para determinadas situaciones que ya no vuelve a utilizar más. Por su parte, Menandro emplea una cierta cantidad limitada y simple que se repite frecuentemente. La causa podría estar en el tipo de acercamiento de cada autor a la lengua conversacional, así Menandro se habría acercado más a la expresión de la función fática de la prosa, mientras que Aristófanes habría hecho lo mismo con la de la tragedia. ${ }^{23}$ Nos queda destacar cuáles son los vocativos más referidos y empleados por mujeres en cada poeta: en Aristófanes son

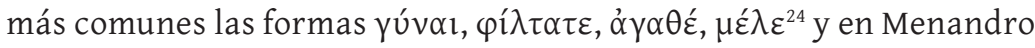

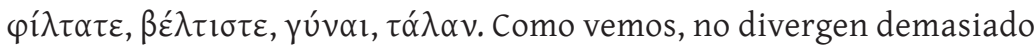
en lo que respecta a la dicción femenina.

Si nos paramos a ver entre todos los rasgos del sociolecto femenino cuáles son los que más destacan, sin duda uno de ellos es el uso abundantísimo del dual. Como sabemos, su utilización es un rasgo propio de la lengua familiar y, además, arcaizante, lo cual casaría con la concepción que hemos visto de que la dicción de las mujeres tiene poco contacto con las innovaciones de la lengua, de manera que se mantiene más "anticuada" con respecto a la de los hombres. De igual forma, el hecho de que pertenezca a la dicción familiar hace que no sólo sea empleado por mujeres, sino también por esclavos, campesinos o personajes afeminados. Ejemplos de duales los encontramos en la

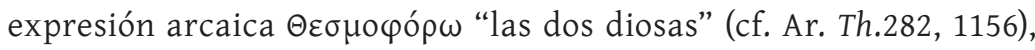

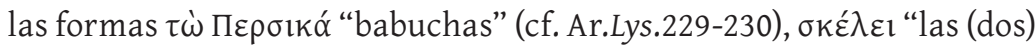
piernas" (cf. Ar.Ec.265), $\tau \omega \dot{\omega} \varphi \theta \alpha \lambda \mu \grave{\omega}$ "los (dos) ojos” (cf. Ar.Lys.298), los pronombres $\tau \alpha \tilde{i} v \delta \varepsilon$ (cf. Ar.Ec.1106), $\alpha \dot{u} \tau \alpha \tilde{i} v$ (cf. Ar.Th.950), verbos como $\mu \varepsilon \tau \alpha \pi \varepsilon ́ \mu \psi \varepsilon \sigma \theta 0 v$ "hacer venir", "ir a buscar" (cf. Ar.Pl.609). Es interesante

23 Dickey 1995: 264-266.

24 Aunque es bastante frecuente en Aristófanes, no tenemos una idea clara de su significado, pues los contextos en los que aparece no nos dan mucha información sobre él. Dickey 1996: 160. 
remarcar que, en el caso de Aristófanes, el uso del dual es confuso, pues podemos encontrar duales y plurales indistintamente, de manera que en ocasiones encontramos construcciones en las que se combinan de manera incoherente elementos en plural con otros en dual y viceversa, como sujetos en plural y verbos en dual o sujetos en dual y verbos en plural; y lo mismo ocurre con los participios. Así pues, es frecuente el hecho de que aparezca un plural donde esperaríamos un dual y a la inversa, conviviendo de esta manera rasgos lingüísticos arcaicos con otros más innovadores. ${ }^{25}$

En la comedia también podemos apreciar la presencia de verbos de naturaleza esencialmente "femenina", es decir, con un marcado valor expresivo debido a su pertenencia al ámbito de la lengua familiar y vulgar. Es el caso de formas como koเkú $\lambda \lambda \omega$ "mirar boquiabierto/a"

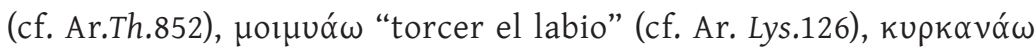

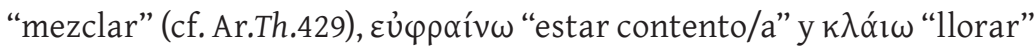
(cf. Men.Pk.188-189). También son formas típicas aquellas que implican actividades únicamente desarrolladas por mujeres, como $\psi \omega \mu$ í $\zeta \omega$ "dar la comida a pedacitos"26 (cf. Ar.Lys.19), kvéw "estar embarazada"

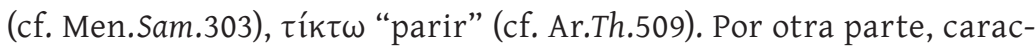
terística típicamente atribuida a las féminas es su gran e insaciable apetito sexual, lo cual queda reflejado en la aparición de expresiones

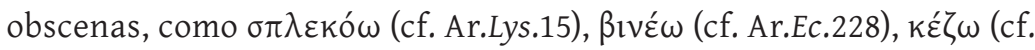

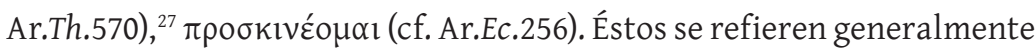
a la unión sexual ("hacer el amor", “joder") y son muy frecuentes en los parlamentos femeninos.

25 López Eire 1991: 21-26.

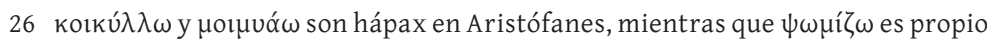

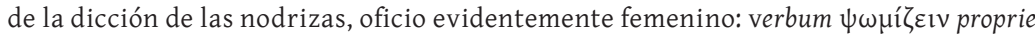
dicitur de nutricibus infantulos alentibus. Van Leeuwen 1900: 128.

27 Lo usa Mensíloco, pero no olvidemos que en este momento se encuentra travestido, así que está imitando la dicción de las mujeres. Cf. Ar.Th.267-268: ү̣v $\lambda \alpha \lambda$ ṇऽ $\delta$,

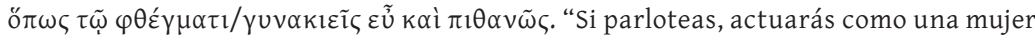
con la voz como es debido y de un modo convincente". 
Otro elemento en el que se observan rasgos del sociolecto femenino lo constituyen las fórmulas de juramentos. Como sabemos, generalmente en función de sus ámbitos de actuación hay divinidades reservadas más al culto por parte de las mujeres (diosas de la fertilidad, del matrimonio, de los alumbramientos, etc.), y otras por los hombres (dioses de la guerra, el comercio, la navegación, etc.), siendo algunas exclusivamente veneradas por cada género y otras por ambos. En la comedia de Aristófanes vemos dos casos característicos en los que destaca esta distinción. Nos referimos a los vv.155-160 de Asambleístas en los que una mujer, que se supone que tiene que hacerse pasar por hombre, pronuncia un juramento por las Dos Diosas, denotando su naturaleza femenina. Cuando es reprendida por Praxágora, pasa a jurar por Apolo, divinidad de culto esencialmente masculino. También en Tesmoforiantes, cuando Mnesíloco, una vez travestido y tras colarse en el Tesmoforio, adopta fórmulas de juramento femeninas. Por otra parte, por quien más juran las mujeres en Aristófanes es por Zeus y en su corpus de once comedias vemos que los juramentos por este dios suman $63 .{ }^{28}$ Es de suponer que jurar por la máxima divinidad Olímpica no es exclusivo del sector femenino, ya que también los hombres juran por Zeus en la mayoría de los casos, por lo que sería una divinidad de culto "mixto". En Menandro sólo se observan dos casos en los que personajes femeninos juran por Zeus: el v.34 de El labriego y el v.757 de La rapada. Seguidamente por quien más juran las féminas es por las Dos Diosas, es decir, Deméter y su hija Koré o Perséfone, y precisamente este juramento es tan solo pronunciado por mujeres tanto en Aristófanes como en Menandro. No ocurre lo mismo con el juramento sólo por Deméter, pues en Aristófanes es únicamente puesto en boca de hombres, en especial labriegos. ${ }^{29}$ En Menandro puede aparecer usado tanto por hombres como por mujeres, aunque en éste último caso en menor medida (cf.

28 Sommerstein 1995: 65.

29 Hay que tener en cuenta el ámbito de actuación de esta diosa. Cf. Ar.Pl.364. 
Men.Epit.955). Le siguen los juramentos por Afrodita, Ártemis, Hécate y diosas menores atenienses, como Aglauro y Pándrosos, que sólo son utilizados por mujeres en las comedias de ambos poetas.

Para acabar nuestro estudio nos queda hablar de las construcciones sintácticas empleadas por los personajes femeninos. En términos generales, las mujeres de la comedia tienden a pronunciar enunciados breves con una estructura sintáctica básica, además, abundan más las frases exclamativas e interrogativas que las enunciativas, lo que casaría con el carácter emotivo que hemos visto atribuido a la dicción femenina. Las estructuras sintácticas de uso femenino más reconocibles y comunes son las oraciones interrogativas introducidas por el pronombre cí y el

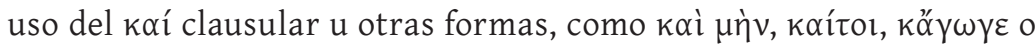
$\kappa \tilde{\alpha} \tau \alpha$ a comienzo de frase (cf. Ar.Ec.30-100), la aparición cambiante de pronombres personales como sujetos (cf. Ar.Lys.479-489), o elisiones de elementos principales de la oración (cf. Ar.Lys.509). También encontramos gran abundancia de la interjección $\tilde{\omega}$, que da intensidad emotiva, e incluso patetismo o afectación "trágica", a los parlamentos femeninos y afeminados en ambos cómicos, y de las partículas $\tau 01,{ }^{30} \gamma \varepsilon$ y $\delta \varepsilon$, que darían un cierto énfasis cómico a las frases pronunciadas. ${ }^{31}$ Siguiendo con las interjecciones, destaca en Menandro el uso de la partícula $\delta \ddot{\imath} \tau \alpha$ como refuerzo de negación (cf. Men.Dys.591; Pk.786, 976). ${ }^{32}$ Por último, llama también la atención el uso abundante de conjunciones subordinadas y el paso repentino del discurso narrativo al discurso directo (cf. Ar.Lys.514-516). ${ }^{33}$

Llegados a este punto podemos extraer varias conclusiones. Hemos visto que los poetas cómicos saben caracterizar de forma verosímil a sus personajes, de manera que no sólo reconocemos a un esclavo, un ciudadano o una mujer por su indumentaria o sus actos, sino también

30 Duoux 2004: 140-141.

31 Sommerstein 1995: 81.

32 Macua 1997: 158, 160.

33 Nieddu 2001: 204. 
por su forma de hablar. Por tanto, existen varios sociolectos en la comedia perfectamente reconocibles, que atienden a los diversos estratos que conformaban la sociedad ateniense. Por su parte, la caracterización del sociolecto femenino responde en términos generales a los tópicos tradicionales sobre la mujer, de manera que los rasgos que encontramos no corresponderían exactamente a los que caracterizaron la lengua de las mujeres de la antigua Atenas. Es más, hay que tener en cuenta que la influencia de la capacidad inventiva y creadora de cada poeta. Los autores que hemos estudiado coinciden en que, tanto Aristófanes como Menandro, reflejaron y caracterizaron el sociolecto femenino en sus comedias, aunque éste no sea tan reconocible como otros sociolectos. La intención de todo ello es remarcar, en el ámbito de la representación teatral, que quien está hablando es una mujer o un hombre afeminado y/o travestido y, sobre todo, hacer reír a los espectadores. También hemos visto que el lenguaje de la mujer pertenece al ámbito de la lengua familiar, el cual engloba también a la lengua de los esclavos y de los niños, pero en la comedia no es únicamente usado por féminas, pues también es puesto en boca de hombres como Agatón o Mnesíloco. El lenguaje familiar pertenece al nivel de las personas sin una esmerada cultura, y su rasgo más característico es la presencia de arcaísmos. Así pues, las mujeres empleaban un ático arcaizante y la causa se debería a su situación social: al estar retraídas (que no excluidas) en la sociedad y no frecuentar el ámbito público de la misma manera que los hombres, no podían asimilar las innovaciones del lenguaje que se estaban desarrollando y dando a conocer, por lo que la comedia nos hace ver que la dicción femenina está en cierta manera fosilizada.

La concepción tradicional de que la mujer es un ser más sensible que el hombre da pie a que los personajes femeninos de Aristófanes y Menandro usen un lenguaje emotivo, que implica tanto el nivel léxicosemántico como el sintáctico-gramatical. De esta manera, hemos examinado verbos que se refieren a su naturaleza de mujer, como alimentar, parir, etc., el uso de adjetivos y expresiones fáticas muy expresivos, la 
abundancia de frases exclamativas e interrogativas en detrimento de las enunciativas, así como el empleo de fórmulas de juramento exclusivamente utilizados por mujeres, que denotan rasgos auténticos de la sociedad en la que habían dioses especialmente venerados por las mujeres, otros por los hombres y otros por ambos sexos. Nos queda decir que Aristófanes y Menandro guardan muchas semejanzas, pues emplean casi los mismos recursos siguiendo el bagaje cómico tradicional. Sin embargo, en Menandro observamos que, aparte de que el griego empleado ha evolucionado y no resulta tan creativo como sí es el poeta de la Archaia, hay una cierta concepción más positiva y profunda de la mujer.

\section{BIBLIOGRAFÍA}

Bain, D. (1984), “Female speech in Menander", Antichton 18: 24-42.

Cortés Gabaudán, F. (2005), "La mujer ateniense vista desde la oratoria", en J. María Nieto Ibáñez (coord.), Estudios sobre la mujer en la cultura griega y latina. León: 39-62.

Dickey, E. (1995), "Forms of address and conversational language in Aristophanes and Menander", Mnemosyne 54.3: 257-271.

Dickey, E. (1996), Greek Forms of Address. From Herodotus to Lucian. Oxford.

Dover, K. J. (1987), Greek and the Greeks: Collected Papers, vol.1. Oxford.

Duoux, Y. (2004), “Langage de femmes et d'hommes en grec ancien: l'exemple de Lysistrata", in J.H.W. Penney (ed.), Indo-European perspectives. Studies in Honour of Anna Morpurgo-Davies. Oxford: 131-145.

Fögen, T. (2010), “Female Speech", in E.J. Bakken (ed.), A Companion to the Ancient Greek Language. Oxford: 311-320.

López Eire, A. (1986), “La lengua de la comedia aristofánica”, Emerita 54.2: 237-274.

López Eire, A. (1991), Ático, koiné y aticismo. Estudios sobre Aristófanes y Libanio. Murcia. 
Macua Martínez, E. (1997), “La caracterización lingüístico-estilística en Menandro”, Veleia 14: 145-162.

Melero Bellido, A. (1984), "Niveles de lengua y estilo en la comedia aristofánica", en Estudis en memoria del professor Manuel Sanchis Guarner: estudis de llengua i literatura, vol. 2. Valencia: 203-210.

Mossé, C. (1990), La mujer en la Grecia Clásica. Madrid.

Redondo Sánchez, J. (1997), "Sociolecto y sintaxis en la comedia aristofánica", en Antonio López Eire (ed.), Sociedad, Política y Literatura: Comedia Griega Antigua. Salamanca: 313-328.

Redondo Sánchez (2002), "El sociolecte femení a la comèdia aristofánica", Quaderns de Filologia: Estudis Lingüístics 7: 201-224.

Sommerstein, A. H. (1995), “The language of Athenian women”, en F. de Martino-A. H. Sommerstein (eds.), Lo spettacolo delle voci. Bari: 61-85.

Sommerstein, A. H. (2009), Talking about Laughter: and Other Studies in Greek comedy. Oxford.

Willi, A. (2003), The languages of Aristophanes. Aspects of Linguistic Variation in Classical Attic Greek. Oxford.

Van Leeuwen, J. (1900), Aristophanis Equites. Cum prolegomenis et commentariis. Leiden. 